\title{
BMJ Open Cohort profile: a migratory cohort study of US Marines who train in Australia
}

\author{
Alyssa Chan-Cuzydlo, ${ }^{1}$ Dustin J Harrison, ${ }^{2}$ Brian L Pike, ${ }^{2}$ Bart J Currie,,${ }^{3,4}$ \\ Mark Mayo, ${ }^{5}$ Mark G Salvador, ${ }^{1}$ William R Hulsey, ${ }^{1}$ Joseph Azzarello, ${ }^{6}$ Jeffrey Ellis, ${ }^{6}$ \\ Daniel Kim, ${ }^{6}$ William King-Lewis, ${ }^{6}$ Jessica Nicole Smith, ${ }^{6}$ Barbara Rodriguez, ${ }^{6}$ \\ Ryan C Maves, ${ }^{7}$ James V Lawler, ${ }^{8}$ Kevin L Schully (i) ${ }^{9}$
}

To cite: Chan-Cuzydlo A, Harrison DJ, Pike BL, et al. Cohort profile: a migratory cohort study of US Marines who train in Australia. BMJ Open 2021;11:e050330. doi:10.1136/ bmjopen-2021-050330

- Prepublication history and additional supplemental material for this paper are available online. To view these files, please visit the journal online (http://dx.doi.org/10.1136/ bmjopen-2021-050330)

Received 17 February 2021 Accepted 24 August 2021

Check for updates

(C) Author(s) (or their employer(s)) 2021. Re-use permitted under CC BY-NC. No commercial re-use. See rights and permissions. Published by BMJ.

For numbered affiliations see end of article.

Correspondence to Dr Kevin L Schully; kevin.I.schully.civ@mail.mil

\section{ABSTRACT}

Purpose In 2012, US Marines and Sailors began annual deployments to Australia to participate in joint training exercises with the Australian Defence Force and other partners in the region. During their training, US service members are exposed to a variety of infectious disease threats not normally encountered by American citizens. This paper describes a cohort of US Marines and Sailors enrolled during five rotations to Australia between 2016 and 2020.

Participants Study participation is strictly voluntary. Group informational sessions are held prior to deployment to describe the study structure and goals, as well as the infectious disease threats that participants may encounter while in Australia. All participants provided written informed consent. Consented participants complete a pre-deployment questionnaire to collect data including basic demographic information, military occupational specialty, travel history, family history, basic health status and personal habits such as alcohol consumption. Blood is collected for serum, plasma and peripheral blood mononuclear cells (PBMC) processing. Data and specimen collection is repeated up to three times: before, during and after deployment.

Findings to date From the five rotations that comprised the 2016-2020 Marine Rotational Force-Darwin, we enrolled 1289 volunteers. Enrolments during this period were overwhelmingly white male under the age of 24 years. Most of the enrollees were junior enlisted and noncommissioned officers, with a smaller number of staff non-commissioned officers and commissioned officers, and minimal warrant officers. Over half of the enrollees had occupational specialty designations for infantry. Future plans In the future, we will screen samples for serological evidence of infection with Burkholderia pseudomallei, Coxiella burnetii, Ross River virus, SARSCoV-2 and other operationally relevant pathogens endemic in Australia. Antigenic stimulation assays will be performed on PBMCs collected from seropositive individuals to characterise the immune response to these infections in this healthy American population.

\section{INTRODUCTION}

In recent years, the US Department of Defense (DoD) has expanded strategic focus to new theatres of operation in Asia and the Global South, regions with a significant burden of severe endemic infectious diseases and a high risk of emerging infectious diseases. To

\section{Strengths and limitations of this study}

We are conducting an observational study of US Marines who train in Australia.

- Any US service member who is scheduled to deploy, or has deployed to Australia, is eligible.

- Gaps in sample set are filled by the Department of Defense Serum Repository.

- The study is an agile platform for Force Health Protection surveillance studies.

Reliance on self-reported information is a limitation.

counter that threat, DoD force health protection (FHP) programmes implement a suite of preventive measures designed to protect US service members deployed overseas. The DoD defines FHP as 'a framework that describes procedures for assessing the types of hazards, the exposure and populations at risk, and the monitoring of the health of all personnel deployed'. ${ }^{1}$ This implies that accurate characterisation and understanding of hazards provides the foundation for effective interventions. While integrated risk assessment strategies for hazardous chemicals and toxic materials have long been used to manage force health in the past, risk assessment strategies for biological threats are not consistently applied.

Biosurveillance is a key component of the military's approach to prevent infections during deployments. For example, arthropodborne diseases such as malaria, dengue, leishmaniasis and scrub typhus constitute a significant threat to military forces serving in endemic areas. ${ }^{2-8}$ Vector surveillance, identifying pathogens within their arthropod vector, can rapidly identify pathogenic threats endemic to a new theatre of operation. ${ }^{9}$ As a working example, vector surveillance is credited for characterising the threat of leishmaniasis to coalition forces in Iraq, where mitigation strategies dramatically decreased the incidence of leishmaniasis cases. ${ }^{10}$ Similar 


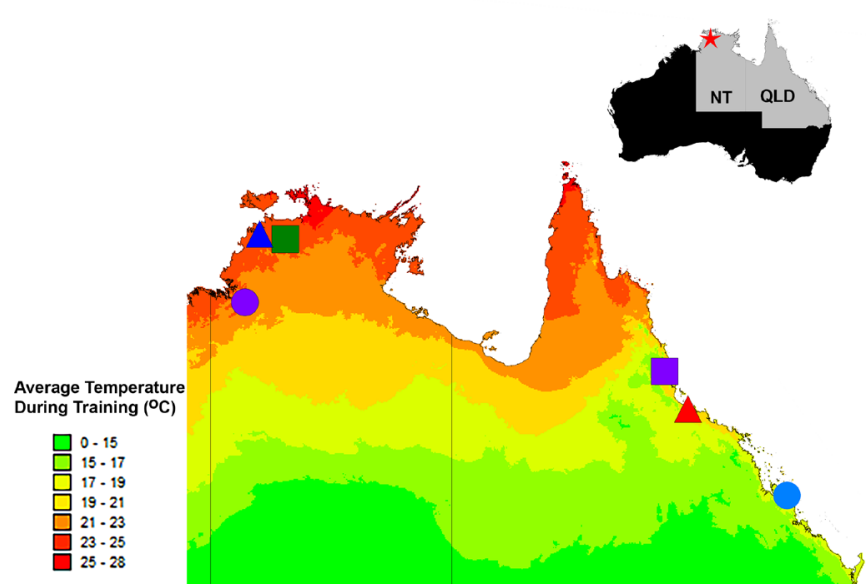

Figure 1 Maps of Australia. The inset highlights the Northern Territory (NT) and Queensland (QLD), with Darwin indicated by a red star. Below, a temperature $\left({ }^{\circ} \mathrm{C}\right)$ map of NT and QLD representing the average temperature during the training period. The main training areas in the NT of Bradshaw (purple circle), Kangaroo Flats (blue triangle), and Mt. Bundey (green square); as well as in QLD, Tully (purple square), Townsville (red triangle), and Shoal Water Bay (blue circle) are indicated. Map was generated by DIVA GIS V.7.5.

surveillance programmes for zoonoses (Coxiella burnetii), water-borne infections (leptospirosis, schistosomiasis), and respiratory infections (influenza, tuberculosis and more recently COVID-19) have proven valuable for characterising the threat of diseases with military relevance. ${ }^{11}$

In 2012, US Marines began annual deployments to Darwin, Australia, located in the Top End region of Australia's Northern Territory (figure 1). Deployed units participate in joint training exercises with the Australian Defence Force and other partners in the Indo-Pacific Region with the overall goal of improved interoperability. The Top End of the Northern Territory covers an area of approximately $500000 \mathrm{~km}^{2}$, with a coastline of over $10000 \mathrm{~km}$. The population is around 200000 people with around 150000 living in the coastal capital city of Darwin $\left(12^{\circ} \mathrm{S}\right.$ latitude) and its surrounds, which include the military bases housing Marine Rotational Force-Darwin (MRF-D). The climate of the Top End is described as the 'wet-dry' tropics, with a monsoonal wet season from November through April, followed by the dry season with minimal rain. Darwin is closer to many Southeast Asian cities than it is to Sydney and Melbourne in southern Australia. Townsville ( $19^{\circ} \mathrm{S}$ latitude) in north Queensland on the east coast of Australia also cycles between a wet and dry tropical climate.

MRF-D began as a modest force of approximately 200 Marines and Sailors, but since has gradually increased to its target size of approximately 2500 US service members. The exact composition of each rotation differs each year. Two consistent features of each rotation is the involvement of a battalion-sized ground combat element (GCE) and an air combat element (ACE). Additional supporting units such as a logistics combat element and artillery units attach once in Australia. At this time, MRF-D arrives in April and departs in October. Therefore, to date, MRF-D has avoided the northern Australian wet season and there is very little rainfall exposure during their rotation. During the deployment, units are engaged in prolonged field exercises with regular and ongoing exposure to soil, dust, surface water and arthropods.

Australia has a variety of infectious disease threats rarely encountered by US expeditionary forces. For example, the tropical north of the Northern Territory is considered a hyper-endemic area for Burkholderia pseudomallei, the bacterium that causes the disease melioidosis. B. pseudomallei is a gram-negative soil saprophyte and is common in the soil of the northern Northern Territory and other tropical areas of Australia. The spectrum of melioidosis ranges from asymptomatic infection to severe sepsis, and modelling has predicted approximately 89000 deaths per year globally. ${ }^{12}$ Darwin has the highest reported incidence of melioidosis of any city globally, with annual rates up to 50 per 100000 population. ${ }^{13}$ B. pseudomallei also has a long history as a threat to military forces, including over 300 documented active cases in US forces during the Vietnam War. Furthermore, serological surveys of Vietnam War veterans suggest hundreds of thousands of additional asymptomatic B. pseudomallei infections with the potential for latency and reactivation even decades later. ${ }^{14-19}$ Underscoring the need for FHP surveillance of MRF-D, we recently demonstrated that US Marines are experiencing asymptomatic infection with B. pseudomallei in Australia by screening serum samples obtained from the DoD Serum Repository (DoDSR) for antibodies directed against $B$. pseudomallei antigens. ${ }^{20}$ We have also identified one potential case of acute melioidosis in a Marine returning from Australia as part of MRF-D. ${ }^{21}$

Here, we describe a migratory cohort enrolled in an observational study of US Marines and Sailors who deploy to Australia for a period of 6 months. To date, 1289 volunteers have consented to participate. Up to three times, pre-deployment, mid-deployment and post-deployment, participants have blood drawn and respond to questionnaires concerning personal history, deployment history and demographics. Recruitment and consent are permitted at any point before, during or after deployment. This study was originally conceived as an FHP study for a single deployment-related pathogen (B. pseudomallei) for the purposes of characterising the risk of melioidosis to MRF-D as well as identifying novel correlates of immunity to $B$. pseudomallei in a healthy American military population. However, the eligibility and consent structure of our study has allowed the focus to expand as needed, resulting in an agile platform for FHP disease surveillance in US Expeditionary Forces.

\section{COHORT DESCRIPTION}

\section{Participants, recruitment and consent}

Active duty Marines and Sailors who have deployed or were scheduled to deploy to Australia were eligible for recruitment. 
Participation was strictly voluntary. Group informational sessions were held to describe the study structure and goals, as well as the infectious disease threats they may encounter while in Australia. Particular focus was placed on B. pseudomallei and melioidosis. Throughout the recruitment process, potential volunteers were repeatedly reminded that participation was voluntary. Active duty members of the study team did not wear uniforms and made no mention of rank in the presence of potential participants.

Participants provided written informed consent. As part of the consent process, participants could authorise their samples to be used for the B. pseudomallei study only, for other studies related to their deployment to Australia or for any future Institutional Review Board-approved studies.

\section{Questionnaire}

Consented participants were given a questionnaire to collect data including basic demographic information (sex, age, birthplace, race, ethnicity, rank), military occupational specialty (MOS), travel history (personal travel and prior deployments), family history (diabetes, chronic liver disease, kidney disease), basic health status (fever, cough, joint pain, headache, chest pain, skin disease), and personal habits such as alcohol consumption. Predeployment and post-deployment questionnaires can be found in the online supplemental material.

\section{Study schedule}

If the MRF-D training schedule allowed, the study team travelled to Australia at the approximate midpoint of the deployment. There, the study team followed up with enrolled participants for additional blood draws and questionnaires. Following redeployment to their home base, the study team again engaged the participants in order to obtain information and post-deployment blood samples. Mid-deployment and post-deployment questionnaires included the locations of specific training areas as well as any exposures they may have experienced (surface water, dust, soil) in Australia. The protocol was structured to allow for additional recruitment and consent before, during and after the rotation. Therefore, additional recruitment and consent occurred throughout the process. Individuals who enrolled after the study pre-deployment enrolment visit can provide consent for the study team to obtain pre-deployment serum from the DoDSR. ${ }^{20} 22$

\section{Sample collection and processing}

Blood was collected by trained phlebotomists and consisted of $10 \mathrm{~mL}$ of blood in a red cap serum separator tube and two $10 \mathrm{~mL}$ green top $\mathrm{LiH}$ plasma tubes. Samples collected within the contiguous USA were centrifuged onsite and shipped overnight to the Naval Medical Research Center in Frederick, Maryland. Samples collected in Australia were processed at the Menzies School of Health Research in Darwin. Serum and plasma were removed and stored

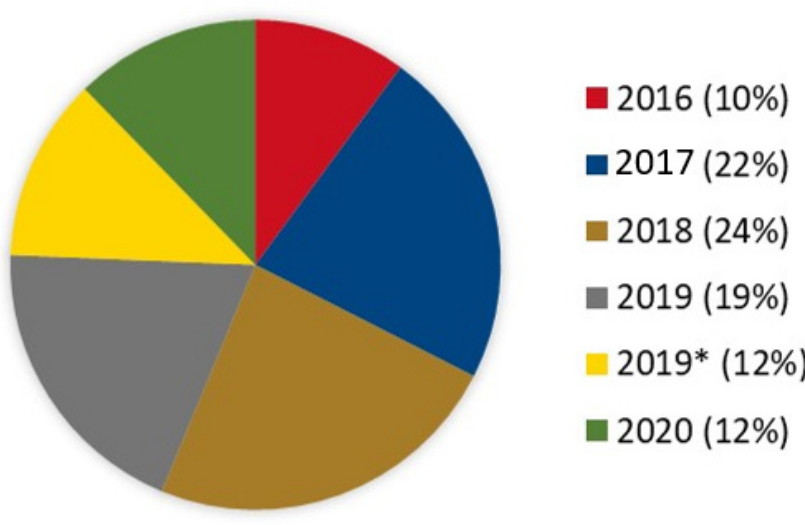

Figure 2 Enrolment distribution per deployment year. Enrolment broken down by year. 2019* indicates a force enhancement to the 2019 rotation.

in aliquots, while peripheral blood mononuclear cells (PBMC) were cryopreserved for future use.

Because some study participants enrolled while in Australia are augmentees from different home units, they were frequently unavailable for follow-up blood sampling. At any stage in the schedule, a volunteer's official duties may prevent follow-up blood draws, as the training schedule always takes precedence over the study. For individuals who provided specific consent to do so, gaps in our sample collection were filled by the DoDSR. ${ }^{20}{ }^{22}$

\section{Data}

Information from paper informed consent forms was entered into a REDCap Database and $100 \%$ verified by a second authorised user. Information from paper questionnaires was also entered into a REDCap Database. For quality assurance, $10 \%$ of questionnaires are verified by a second authorised user.

\section{Patient and public involvement}

There was no patient or public involvement in the development of this protocol.

\section{RESULTS}

From the five rotations that comprised the 2016-2020 MRF-D, we enrolled a total of 1289 volunteers (figure 2). Enrolments during this period were overwhelmingly male, with 1248 men and 41 women enrolled. Sixty-nine per cent (869 of 1289) of participants described themselves as white/Caucasian (figure 3A). Seventy-six per cent of the participants were under the age of 24 years, while the remainder of the cohort ranged from 25 to 49 years of age (figure $3 \mathrm{~B}$ ).

Ideally, encounters with study volunteers occur three times: prior to deployment at their home base, during deployment while in Australia and post-deployment after returning to their home base. However, due to the structure of our study and the rigours of operational training schedules, participation was variable. For rotation year 2016, only the post-deployment time point was 
A

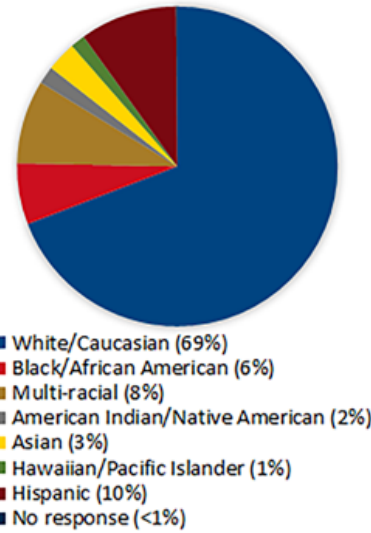

B

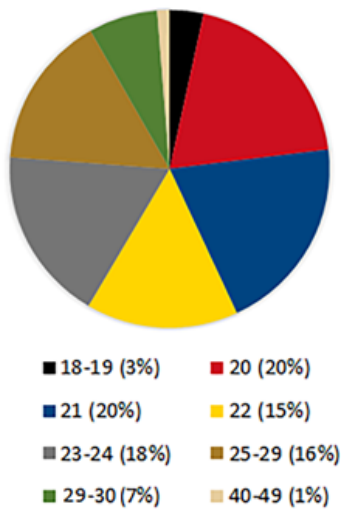

Figure 3 Enrolment demographics distributions of $(A)$ race and $(\mathrm{B})$ age.

completed. All time points were completed for rotation years 2017 and 2018. During rotation year 2019 and 2020, no mid-deployment time point was able to be captured. Additionally, in 2019, a force enhancement battalion joined MRF-D in Darwin. These Marines were enrolled post-deployment (figure 2, 2019*). Initial consent was obtained at pre-deployment for 594 (46\%) Marines and Sailors. Additional $173(13 \%)$ volunteers consented at mid-deployment, and $522(41 \%)$ joined our study at postdeployment (table 1A). Enrollee completion for all predeployment, mid-deployment and post-deployment visits, when applicable, was variable each rotation year due to this being a voluntary study. For rotation years where we were able to capture multiple events, most enrollees returned for follow-up study events (table 1B).

The study team had access to members of the GCE during all deployment rotations. During deployment year 2018, we also had access to the ACE. In 2018, 74 volunteers and in 2019, 38 volunteers were from ACE, with the remaining participants being from the GCE. The majority of volunteers were enlisted Marines (figure 4). In terms of MOS, over half of participants were members of the Infantry (table 2).

For $76 \%$ of the cohort (983 of 1289), Australia was their first deployment; 61\% (789 of 1289) had never

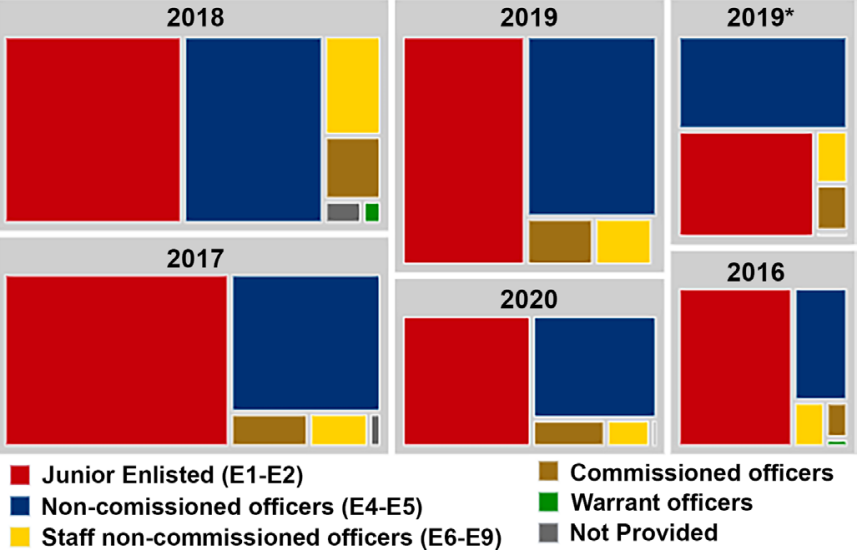

Figure 4 Enrolment rank distribution per deployment year. Distribution of rank at the time of enrolment for each rotational year. 2019* indicates a force enhancement to the 2019 rotation.

previously travelled outside of the USA (deployments and personal travel included). Three hundred six of 1289 $(24 \%)$ had one or more previous military deployments to land-based operations: $60 \%$ (184 of 306) to the IndoPacific (Indo-Pacific Command) region; 48\% (145 of 306 ) to the Middle East (Central Command); $5 \%$ (16 of 306) to Africa (Africa Command); and 10\% (30 of 306) to Cuba (Southern Command) (table 3A). Of the $22 \%$ of the cohort (279 of 1289) with personal travel outside of the continental USA, $29 \%$ had travelled to the Caribbean, $14 \%$ to Southeast Asia and $13 \%$ to Central America (table 3B). A total of $7 \%$ (90 of 1289) of participants were born outside of the USA (table 3C).

While deployed in Australia, participants' training areas were concentrated in the Northern Territory and coast of Queensland as illustrated in figure 1, with many respondents reporting more than one training area. For the $75 \%$ of the cohort that listed training area responses (972 of 1289), the most reported training area with exposure to dust, soil, and/or surface water in the Northern Territory was Mt. Bundey at 74\% (723), followed by $24 \%$ in Kangaroo Flats and $21 \%$ in general Darwin (table 4 ).

Table 1 (A) Initial consent provided by volunteer at pre-deployment, mid-deployment or post-deployment visit; (B) number of volunteers mid-deployment, or post-deployment visit and total enrolments for that year

\begin{tabular}{|c|c|c|c|c|c|c|}
\hline & \multicolumn{3}{|l|}{ (A) Consent } & \multicolumn{3}{|l|}{ (B) Follow-up } \\
\hline & Pre-deployment & Mid-deployment & Post-deployment & Mid-deployment & Post-deployment & Total \\
\hline 2016 & ND-p & ND-m & 130 & ND-m & 130 & 130 \\
\hline 2018 & 134 & 155 & 17 & 247 & 211 & 306 \\
\hline 2019 & 110 & ND-m & 140 & ND-m & 199 & 250 \\
\hline 2020 & 148 & ND-m & 10 & ND-m & 133 & 158 \\
\hline
\end{tabular}

*Indicates force enhancement for 2019 MRF-D.

MRF-D, Marine Rotational Force-Darwin; ND-m, no enrolments, mid-deployment; ND-p, no enrolments, pre-deployment. 
Table 2 Marines Corps military occupational specialty (MOS) distribution for each deployment year

\begin{tabular}{|c|c|c|c|c|c|c|c|}
\hline & 2016 & 2017 & 2018 & 2019 & 2019* & 2020 & Total \\
\hline Infantry & 106 & 178 & 133 & 122 & 103 & 120 & 762 \\
\hline Hospital corpsman & 3 & 28 & 19 & 21 & 12 & 16 & 99 \\
\hline Communications & 6 & 36 & 14 & 16 & 16 & 3 & 91 \\
\hline Motor transport & 2 & 11 & 24 & 15 & 2 & 4 & 58 \\
\hline Aircraft maintenance & & & 39 & 19 & & & 58 \\
\hline Field artillery & & 4 & 18 & 23 & 4 & & 49 \\
\hline Personnel and administration & 4 & 12 & 8 & 3 & 2 & 1 & 30 \\
\hline Avionics and aviation & & & 18 & 9 & & & 27 \\
\hline Intelligence & & 6 & 4 & 4 & 2 & 3 & 19 \\
\hline Engineer, construction, facilities and equipment & & & 5 & & 12 & & 17 \\
\hline Logistics & 2 & 3 & 5 & 1 & 1 & 4 & 16 \\
\hline Pilot & & & 8 & 7 & & & 15 \\
\hline Miscellaneous MOSs & 2 & 2 & 5 & 3 & 1 & 2 & 15 \\
\hline Supply administration and operations & & 2 & 1 & 4 & & 2 & 9 \\
\hline Chemical, biological, radiological and nuclear defence & 2 & 2 & & & 1 & 2 & 7 \\
\hline Ammunition & & 3 & 2 & & & 1 & 6 \\
\hline Ground ordinance maintenance & 2 & 2 & 2 & & & & 6 \\
\hline Ground electronics maintenance & 1 & & 1 & 3 & & & 5 \\
\hline
\end{tabular}

*Indicates a force enhancement to the 2019 rotation.

In Queensland, the most identified locations include $17 \%$ in Shoal Water Bay and 13\% in Townsville.

\section{Strengths and limitations}

As demonstrated by the current SARS-CoV-2 pandemic, infectious diseases can weaken a military's readiness as much as any weapon. FHP studies are essential to provide biothreat situational awareness to forces operating in Outside Continental United States (OCONUS) areas of responsibility. The DoDSR provides an invaluable resource for FHP studies but cannot serve as the sole source of biospecimens and information for deployment-related studies. Prospective studies, such as the one described here, have the potential to provide a depth and breadth of information that would not otherwise be available from archived specimens. For example, not all Marines in MRF-D deploy to Darwin. Each year, a significant number of MRF-D participants engage in training activities outside of Darwin for the entirety of their rotation. These areas differ from Darwin in many ways, including climate (figure 1) and potential biological exposures. Perhaps more importantly, some engage in ship-board activities and their time on land in Australia is limited. In each of these cases, a reported deployment history of 'Australia' would not provide sufficient granularity for useful data analyses. Only a prospective study can accurately determine specific training areas and duration of exposure in these areas. Our direct interaction with expeditionary forces and data collection practices allows us to accurately determine the threats of specific training areas and activities.

Our study began as an observational study for B. pseudomallei infection. However, our protocol's structure presents a model for an agile platform that can be leveraged for a variety of FHP surveillance studies, an especially important feature for threat-rich environments such as the Top End of Australia. In addition to melioidosis, vector-borne viruses (arboviruses) such as Ross River virus are common in tropical Australia. Ross River virus is the most common of the alphaviruses in Australia, occurring almost exclusively in that country. ${ }^{23}$ With a 5 -year mean of 4758.6 cases per year in Australia, Ross River virus may have the most outbreak potential among US Marines. ${ }^{24} \mathrm{Q}$ fever is another important endemic disease, and was first described in Australia in 1937. It is caused by C. burnetii, a gram-negative, obligate intracellular bacterium, which oscillates between an infectious small-cell variant and a replicative large-cell variant. ${ }^{25}$ $\mathrm{Q}$ fever lacks unique clinical signs or symptoms but may present with a wide spectrum of acute and chronic manifestations. ${ }^{26}$ It is endemic to many of the areas where US forces deploy, ${ }^{27}$ and seroprevalence studies clearly demonstrate deployment-related seroconversions in US and UK military personnel in Iraq and Afghanistan. ${ }^{28-31}$ Outbreaks in US service members underpin the need for $Q$ fever to become an important consideration for FHP of US military personnel. ${ }^{32}{ }^{33}$ Specimens from those who provide specific written consent are also used for Ross River virus, $Q$ fever and SARS-CoV-2 FHP surveillance. 
Table 3 Travel outside of the continental USA. (A) Prior deployments: 306 enrollees responded with prior deployments; \% is n/306. (B) Personal travel: 279 enrollees responded with Outside Continental United States (OCONUS) personal travel; \% is $\mathrm{n} / 279$. (C) Birthplace: 90 participants were born outside of the USA; $\%$ is $n / 90$

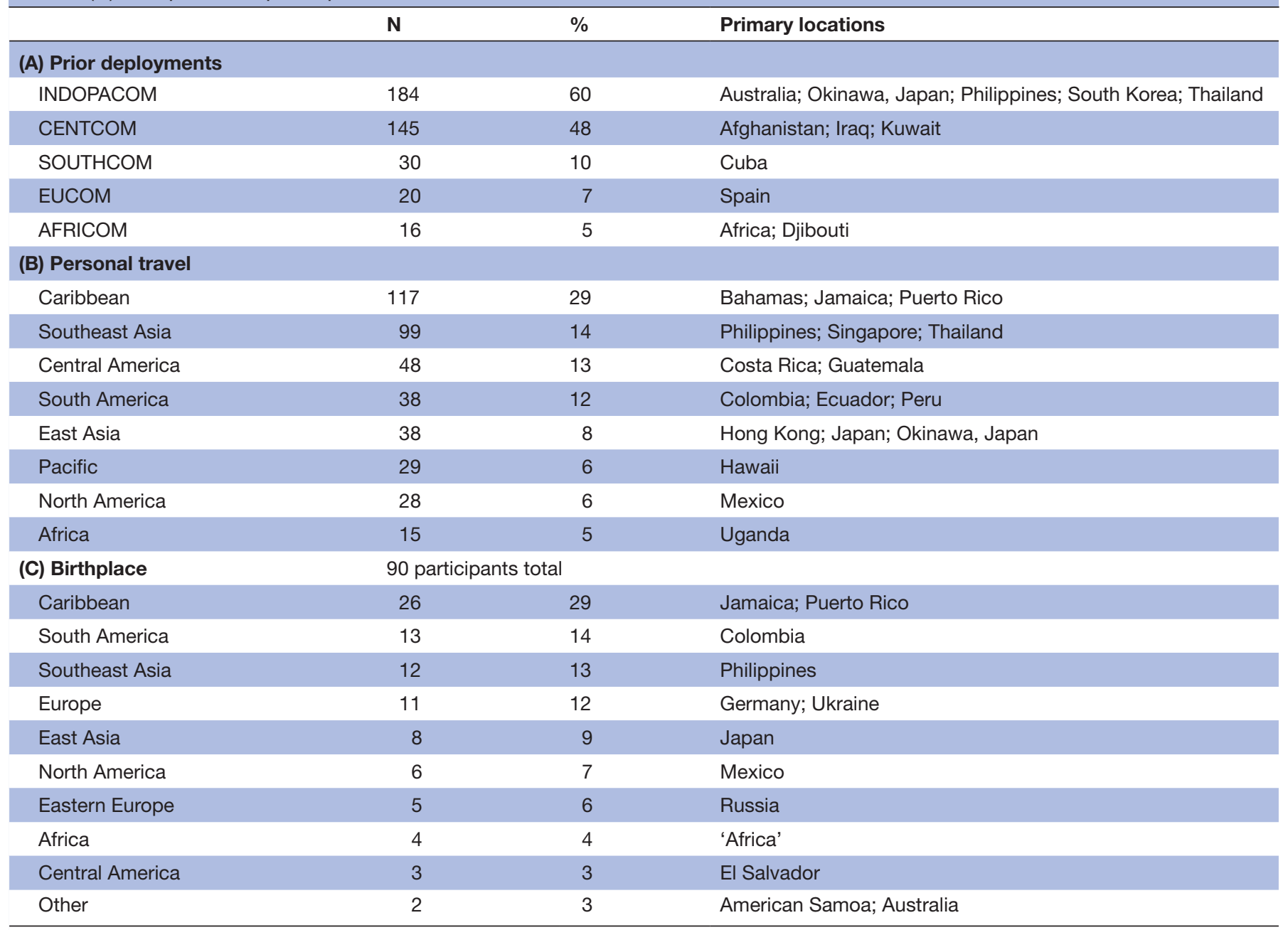

AFRICOM, Africa Command; CENTCOM, Central Command; EUCOM, European Command; INDOPACOM, Indo-Pacific Command; SOUTHCOM, Southern Command.

Our ability to enrol at any point during the MRF-D rotation is a considerable strength of our study. For example, enrolment at various stages provides us with access to MRF-D augments who were not present at pre-deployment, potentially eliminating bias that would result from enrolling

Table 4 Australia training areas where respondents reported being exposed to dust, soil, and/or surface water (\% represented as number of responses out of total enrollees who reported at least one training area, N/972)

\begin{tabular}{lcc}
\hline & & $\%$ \\
\hline Mt. Bundey & 723 & 74 \\
\hline Kangaroo Flats & 229 & 24 \\
Darwin & 202 & 21 \\
Shoal Water Bay & 169 & 17 \\
Townsville & 124 & 13 \\
Bradshaw & 48 & 5 \\
\hline Tully & 44 & 5 \\
\hline
\end{tabular}

exclusively from the main body battalion at pre-deployment. However, the variable participation at each time point that results represents a limitation as well. There are sizeable differences among rotations represented in our cohort. Specifically, the 2016 MRF-D was enrolled approximately 9 months after their return from Darwin. In 2017 and 2018, we completed pre-deployment, mid-deployment and postdeployment activities. In 2019 and 2020, the study team was not able to join MRF-D in Australia but completed predeployment and post-deployment activities with the main body of both rotations. The 2019 rotation also included a force enhancement battalion who joined the main body in Darwin. These Marines were enrolled post-deployment. Still, our ability to obtain missing serum samples from the DoDSR has resulted in very few gaps in our sample repository.

COVID-19 had a significant impact on the 2020 MRF-D. They usually arrive in Australia en masse in April, resulting in a consistent time in country. In previous rotation years, the median time in Australia was 182 days (range 29-213). ${ }^{20}$ In 2020, the battalion first embarked to Okinawa in May. 
Then, following a 2-week quarantine period, they rotated into Darwin in waves of 200 approximately every 2 weeks. On each wave's arrival, they entered a second 2-week quarantine. The entire battalion was present and cleared from quarantine in early August. As a result, not only did the 2020 rotation have a shorter overall time in Australia than previous rotations, but there were also four possible durations of time spent in Australia depending on which flight wave personnel arrived on. This will affect persontime calculations. Finally, the 2020 Marines remained in Darwin for the duration of their training. No MRF-D Marines participated in jungle warfare training, Rim of the Pacific Exercise (RIMPAC), or any other operation outside of the Northern Territory.

In conclusion, our study provides a comprehensive framework for infectious disease threat assessment of immunologically naïve US expeditionary forces who deploy to Darwin, Australia as part of MRF-D. The infectious disease threats that exist in the Northern Territory are well known. However, the potential impact on expeditionary forces operating there remains undetermined. This cohort will provide crucial information and allow for the prioritisation of risks and the development of risk management strategies for expeditionary forces operating in Australia. Furthermore, in addition to risk assessment, analyses of the memory immune response elicited by seropositive individuals will provide insight into a protective immune response required for future medical countermeasure development.

\section{Author affiliations}

${ }^{1}$ The Austere environments Consortium for Enhanced Sepsis Outcomes (ACESO), The Henry M Jackson Foundation for the Advancement of Military Medicine, Bethesda, Maryland, USA

${ }^{2}$ Naval Medical Research Center, Frederick, Maryland, USA

${ }^{3}$ Department of Infectious Diseases, Menzies School of Health Research, Casuarina, Northern Territory, Australia

${ }^{4}$ Department of Infectious Diseases, Royal Darwin Hospital, Casuarina, Northern Territory, Australia

${ }^{5}$ Menzies School of Health Research, Casuarina, Northern Territory, Australia

${ }^{6} 1$ st Marine Division, Marine Corps Base Camp Pendleton, California, USA

${ }^{7}$ Division of Infectious Diseases, Naval Medical Center San Diego, San Diego, California, USA

${ }^{8}$ Division of Infectious Diseases, University of Nebraska Medical Center, Omaha, Nebraska, USA

${ }^{9}$ Austere environments Consortium for Enhanced Sepsis Outcomes (ACESO), Naval Medical Research Center, Silver Spring, Maryland, USA

Acknowledgements We thank the leadership, medical officers, Marines and Sailors who supported and participated in this study. We also thank Vanessa Rigas, Glenda Harrington and Jessica Webb from Menzies, and Wei Huang and Matthew Bell from BDRD for laboratory support. We thank Angelia Cost from the DoD Serum Repository and the Armed Forces Health Sciences Branch.

Contributors AC-C—data curation and manuscript preparation. KS—conception, design, manuscript preparation and project supervision. DH, BP, RCM and JVLproject supervision, manuscript preparation and review. WRH, MGS, JA, JE, DK, WK-L, JNS and BR - project implementation and supervision in the USA, sample collection and preparation, and manuscript review. BJC—project implementation and supervision in Australia, and manuscript preparation and review. MM—project implementation in Australia and manuscript review.

Funding Partial funding received from the Armed Forces Health Surveillance Division (AFHSD), Global Emerging Infections Surveillance (GEIS) Branch, ProMIS ID 2049_16_NA. DTRA CB10400.
Disclaimer RCM, DJH and BCP are military service members and KLS is a federal employee of the US government. This work was prepared as part of their official duties. Title 17 U.S.C. 105 provides that copyright protection under this title is not available for any work of the US government. Title 17 U.S.C. 101 defines a US government work as work prepared by a military service member or employee of the US government as part of that person's official duties.

Map disclaimer The inclusion of any map (including the depiction of any boundaries therein), or of any geographic or locational reference, does not imply the expression of any opinion whatsoever on the part of BMJ concerning the legal status of any country, territory, jurisdiction or area or of its authorities. Any such expression remains solely that of the relevant source and is not endorsed by BMJ. Maps are provided without any warranty of any kind, either express or implied.

Competing interests None declared.

Patient consent for publication Not required.

Ethics approval The prospective study protocol was approved by the Institutional Review Boards of the Naval Medical Research Center and the US Marine Corps, as well as the Human Research Ethics Committee of the Northern Territory Department of Health and Menzies School of Health Research in compliance with all applicable US and Australian federal regulations governing the protection of human subjects.

Provenance and peer review Not commissioned; externally peer reviewed.

Data availability statement № data are available.

Supplemental material This content has been supplied by the author(s). It has not been vetted by BMJ Publishing Group Limited (BMJ) and may not have been peer-reviewed. Any opinions or recommendations discussed are solely those of the author(s) and are not endorsed by BMJ. BMJ disclaims all liability and responsibility arising from any reliance placed on the content. Where the content includes any translated material, BMJ does not warrant the accuracy and reliability of the translations (including but not limited to local regulations, clinical guidelines, terminology, drug names and drug dosages), and is not responsible for any error and/or omissions arising from translation and adaptation or otherwise.

Open access This is an open access article distributed in accordance with the Creative Commons Attribution Non Commercial (CC BY-NC 4.0) license, which permits others to distribute, remix, adapt, build upon this work non-commercially, and license their derivative works on different terms, provided the original work is properly cited, appropriate credit is given, any changes made indicated, and the use is non-commercial. See: http://creativecommons.org/licenses/by-nc/4.0/.

ORCID iD

Kevin L Schully http://orcid.org/0000-0001-5554-0133

\section{REFERENCES}

1 National Research Council. Strategies to protect the health of deployed US forces: assessing health risks to deployed us forces: workshop proceedings. Washington DC: The National Academies Press, 2000.

2 Bavaro MF, Kelly DJ, Dasch GA, et al. History of U.S. military contributions to the study of rickettsial diseases. Mil Med 2005;170:49-60.

3 Corwin A, Soderquist R, Suwanabun N, et al. Scrub typhus and military operations in Indochina. Clin Infect Dis 1999;29:940-1.

4 Burnette WN, Hoke $\mathrm{CH}$, Scovill J, et al. Infectious diseases investment decision evaluation algorithm: a quantitative algorithm for prioritization of naturally occurring infectious disease threats to the U.S. military. Mil Med 2008;173:174-81.

5 Elston DM, Miller SD. Leishmaniasis acquired in the Iraqi theater of operations: lessons learned. Cutis 2004;74:253-5.

6 Kelly DJ, Richards AL, Temenak J, et al. The past and present threat of rickettsial diseases to military medicine and international public health. Clin Infect Dis 2002;34:S145-69.

7 Kitchener S, Leggat PA, Brennan L, et al. Importation of dengue by soldiers returning from East Timor to North Queensland, Australia. J Travel Med 2002;9:180-3.

8 Sanders JW, Putnam SD, Frankart C, et al. Impact of illness and noncombat injury during operations Iraqi freedom and enduring freedom (Afghanistan). Am J Trop Med Hyg 2005;73:713-9.

9 Coleman RE, Hochberg LP, Putnam JL, et al. Use of vector diagnostics during military deployments: recent experience in Iraq and Afghanistan. Mil Med 2009;174:904-20.

10 Coleman RE, Burkett DA, Putnam JL, et al. Impact of phlebotomine sand flies on U.S. Military operations at Tallil Air Base, Iraq: 1. 
background, military situation, and development of a "Leishmaniasis Control Program". J Med Entomol 2006;43:647-62.

11 Murray CK, Horvath LL. An approach to prevention of infectious diseases during military deployments. Clin Infect Dis 2007;44:424-30.

12 Limmathurotsakul D, Golding N, Dance DA. Predicted global distribution of and burden of melioidosis. Nat Microbio/2016;1.

13 Parameswaran U, Baird RW, Ward LM, et al. Melioidosis at Royal Darwin Hospital in the big 2009-2010 wet season: comparison with the preceding 20 years. Med J Aust 2012;196:345-8.

14 Spotnitz M. Disease may be Vietnamese time bomb. Medical World News 1966;7:55.

15 Sanford JP, Moore WL. Recrudescent melioidosis: a Southeast Asian legacy. Am Rev Respir Dis 1971;104:452-3.

16 Mackowiak PA, Smith JW. Septicemic melioidosis. Occurrence following acute influenza A six years after exposure in Vietnam. JAMA 1978;240:764-6.

17 Mays EE, Ricketts EA. Melioidosis: recrudescence associated with bronchogenic carcinoma twenty-six years following initial geographic exposure. Chest 1975;68:261-3.

18 Johnson AB, Ali N. Reactivation of latent melioidosis. Postgrad Med J 1990;66:732-3.

19 Koponen MA, Zlock D, Palmer DL, et al. Melioidosis. Forgotten, but not gone! Arch Intern Med 1991;151:605-8.

20 Schully KL, Burtnick MN, Bell MG, et al. Serological evidence of Burkholderia pseudomallei infection in U.S. Marines who trained in Australia from 2012-2014: a retrospective analysis of archived samples. MSMR 2019;26:8-17.

21 Larson DT, Schully KL, Spall A, et al. Indirect Detection of Burkholderia pseudomallei Infection in a US Marine After Training in Australia. Open Forum Infect Dis 2020;7:ofaa103.

22 Rubertone MV, Brundage JF. The defense medical surveillance system and the Department of defense serum repository: glimpses of the future of public health surveillance. Am J Public Health 2002;92:1900-4.
23 Mackenzie JS, Lindsay MD, Coelen RJ, et al. Arboviruses causing human disease in the Australasian zoogeographic region. Arch Virol 1994;136:447-67.

24 Knope K, Whelan P, Smith D, et al. Arboviral diseases and malaria in Australia, 2010-11: annual report of the National Arbovirus and Malaria Advisory Committee. Commun Dis Intell Q Rep 2013;37:E1-20.

25 McCaul TF, Williams JC. Developmental cycle of Coxiella burnetii: structure and morphogenesis of vegetative and sporogenic differentiations. J Bacteriol 1981;147:1063-76.

26 Derrick EH. "Q" fever, a new fever entity: clinical features, diagnosis and laboratory investigation. Rev Infect Dis 1983;5:790-800.

27 Wallace MR, Hale BR, Utz GC, et al. Endemic infectious diseases of Afghanistan. Clin Infect Dis 2002;34:S171-207.

28 Anderson AD, Baker TR, Littrell AC, et al. Seroepidemiologic survey for Coxiella burnetii among hospitalized US troops deployed to Iraq. Zoonoses Public Health 2011;58:276-83.

29 Newman ENC, Johnstone P, Bridge $\mathrm{H}$, et al. Seroconversion for infectious pathogens among UK military personnel deployed to Afghanistan, 2008-2011. Emerg Infect Dis 2014;20:2015-22.

30 Farris CM, Pho N, Myers TE, et al. Seroconversions for Coxiella and rickettsial pathogens among US Marines deployed to Afghanistan, 2001-2010. Emerg Infect Dis 2016;22:1491-3.

31 Royal J, Riddle MS, Mohareb E, et al. Seroepidemiologic survey for Coxiella burnetii among US military personnel deployed to Southwest and central Asia in 2005. Am J Trop Med Hyg 2013;89:991-5.

32 Gleeson TD, Decker CF, Johnson MD, et al. Q fever in US military returning from Iraq. Am J Med 2007;120:e11-12.

33 Faix DJ, Harrison DJ, Riddle MS, et al. Outbreak of $Q$ fever among US military in Western Iraq, June-July 2005. Clin Infect Dis 2008;46:e65-8. 